18

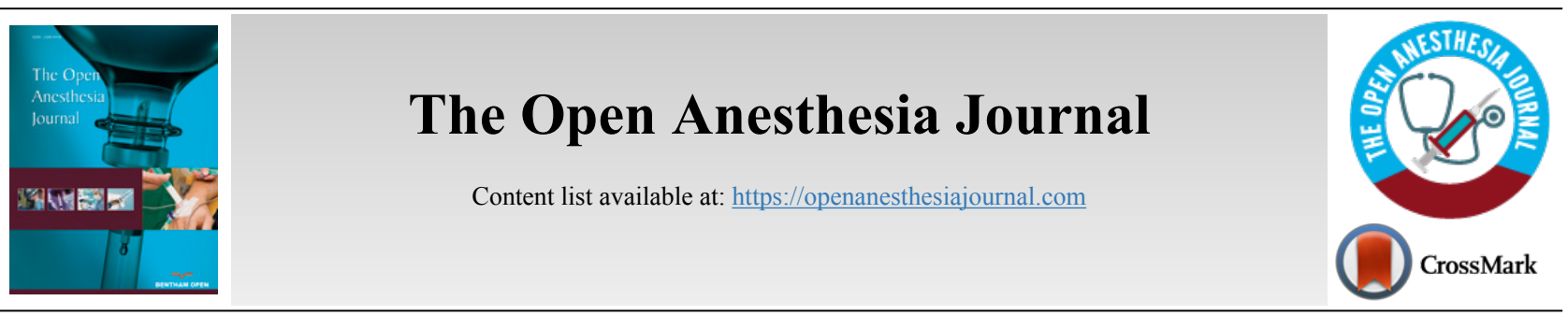

RESEARCH ARTICLE

\title{
Bisoprolol Versus Corticosteroid and Bisoprolol Combination for Prevention of Atrial Fibrillation After On-Pump Coronary Artery Bypass Graft Surgery
}

\author{
Ramy Mahrose ${ }^{1, *}$, Ahmed M. Elsayed ${ }^{1}$ and Mohamed S. Elshorbagy ${ }^{1}$ \\ ${ }^{\prime}$ Department of Anesthesiology, Faculty of Medicine, Ain Shams University, Cairo, Egypt
}

\begin{abstract}
:
Background:

The most common cardiac arrhythmia that happens after on-pump Coronary Artery Bypass Graft (CABG) surgery is Atrial Fibrillation (AF). It is combined with several postoperative complications such as increased incidence of stroke, increased hospital stay and increased costs.

Objectives:

The aim of this study was to look for safe, effective, reliable and well tolerated tools for the prevention of atrial fibrillation after on pump coronary artery bypass surgery.

Patients and Methods:

The study enclosed 176 patients (the age ranges from 40 to 79 years) and scheduled for elective on-pump CABG operations without concomitant procedures. The patients were selected randomly into two equal groups. Group (A) in which bisoprolol was used to prevent atrial fibrillation after surgery. Group (B) in which bisoprolol and hydrocortisone were used for prevention of atrial fibrillation after surgery. For each patient, the following data were collected: gender, preoperative diseases, cardiopulmonary bypass time, intraoperative cross clamp time, Left internal mammary Artery usage, incidence of postoperative atrial fibrillation, death, myocardial infarction chest infection and C-reactive protein amount in plasma.
\end{abstract}

Results:

There was a statistically significant decrease in the occurrence of atrial fibrillation in group (B) when compared to corresponding values in group (A). Also, group (B) showed a statistically significant decrease in length of hospital stay in comparison to group (A). C-reactive protein concentrations on the $1^{\text {st }}$ and $2^{\text {nd }}$ postoperative days were lower significantly in group (B) than in group (A). There were no statistically significant differences between both groups regarding gender, preoperative diseases, cardiorespiratory bypass time, intraoperative cross clamp time, Left internal mammary artery usage, death, myocardial infarction and chest infection.

\section{Conclusion:}

This study demonstrated that using bisoprolol and hydrocortisone combination showed greater benefit than the use of bisoprolol only for prevention of postoperative AF after on-pump coronary artery bypass graft surgery.

Keywords: Bisoprolol, Corticosteroid, Atrial fibrillation, Cardiac surgery, Myocardial infarction, Bypass graft surgery.

\section{INTRODUCTION}

The most common kind of arrhythmias after Coronary Artery Bypass Graft (CABG) surgery is Atrial Fibrillation (AF); its incidence is about $20-40 \%$. Although atrial fibrillation is a benign cardiac arrhythmia, haemodynamic instability, an-

\footnotetext{
* Address correspondence to this author at Department of Anesthesiology, Faculty of Medicine, Ain Shams University, Cairo, Egypt; Tel: +201281431097; Email: ramymahrose2@gmail.com
}

xiety, blood clot formation, embolization and prolonged hospital stay may occur for a long time [1].

Many risk factors play a role in the development of atrial fibrillation after cardiac surgery such as advanced age, history of AF, hypertension, smoking, obesity, previous myocardial infarction, right atrial dilatation, low ejection fraction and discontinuation of beta-blocker [2].

After cardiac surgery the pathophysiology of AF is unclear, however, it has been demonstrated to be related to the 
use of heart-lung machine, atrial cannulation, and myocardial ischemia, changes in autonomic tone, inflammation and conservation techniques needed during these procedures [3].

Many pharmacological agents like beta blockers, digoxin, calcium channel blockers, corticosteroids and amiodarone have been used to prevent the appearance AF after coronary artery bypass graft surgery. However, none of those factors has been consistently used as a usual treatment [4].

\subsection{Aim of the Work}

The purpose of the study is the comparison between bisoprolol versus corticosteroid and bisoprolol combination for prevention of atrial fibrillation after on-pump coronary artery bypass graft surgery.

\section{PATIENTS AND METHODS}

The study was conducted at The Cardiothoracic surgery intensive care unit of Ain Shams University hospitals over a period of 6 months. The study protocol was approved by the "research and ethics committee" of anesthesia, intensive care and pain management department, Ain Shams University. Informed consent was obtained from the patients before enrolling in the study.

176 Patients were included in the study. Patients were arbitrarily allotted by computer-generated random variety list into 2 study groups of 88 patients each, the range of age was between 40 and 79 years and were undergoing elective onpump CABG operations without concomitant procedures.

\subsection{Group A}

Patients are given bisoprolol $5 \mathrm{mg}$ orally (P.O.) onthe evening of the operation, then one dose ( $5 \mathrm{mg}$ ) each twentyfour hours throughout the following 2 days.

\subsection{Group B}

Patients received bisoprolol same as group (A), in addition, hydrocortisone $100 \mathrm{mg}$ was intravenously given on the evening of the operation and then $100 \mathrm{mg}$ every eight hours throughout the following 2 days.

\subsection{Exclusion Criteria for the Study Included}

Patients suffering from rhythm abnormalities preoperatively (atrioventricular conduction abnormalities, sick sinus syndrome, history of chronic or intermittent AF), undergoing treatment with classes I and III antiarrhythmic agents preoperatively, receiving drugs for hypertension except Angiotensin Convertor Enzyme (ACE) inhibitors, thyroid disease, renal or hepatic disease, peripheral arterial atherosclerosis, thrombophlebitis, uncontrolled diabetes mellitus, systemic bacterial or fungal infection, active tuberculosis, Cushing's disease, peptic ulcer, psychotic mental disorder, Herpes Simplex keratitis and chronic obstructive lung disease were not included in the study.

\subsection{Intraoperative Technique}

After sedation with diazepam (10 mg intramuscular), radial arterial catheterization, intravenous catheters, and a central venous catheter were introduced within the operating theater. Hemodynamic parameters; monitoring heart rate, mean arterial pressure, rectal temperature, central venous pressure and arterial blood gas throughout the process were observed. Anesthesia was started by fentanyl $(35 \mathrm{mcg} / \mathrm{kg})$ and muscle relaxant using pancronium $(0.1 \mathrm{mg} / \mathrm{kg})$, then endotracheal intubation using ventilation with $100 \%$ oxygen. The median incision of the sternum was used for cardiac exposure. The left internal mammary artery was taken and the saphenous vein was prepared if needed. All operations were using cardiopulmonary bypass and moderate hypothermia $\left(28-32{ }^{\circ} \mathrm{C}\right)$ with flow rates of 2.2-2.4 1/m2 and the mean perfusion pressure of $50-85 \mathrm{~mm} \mathrm{Hg}$. Heart failure was assisted by crystalloid cardioplegia initially $\left(4-8{ }^{\circ} \mathrm{C}, 15 \mathrm{cc} / \mathrm{kg}\right)$ and heart preservation was assisted with $400 \mathrm{cc}$ cold blood Cardioplegia every 20 minutes. The hot shut was used shortly before removing the cross-clamp. The venous cannula was inserted through the right atrial appendix. The arterial cannula was placed within the ascending aorta.

\subsection{Postoperative Monitoring}

Patients were continuously monitored at the intensive care unit with Electrocardiography (ECG), invasive blood pressure and oxygen saturation using finger probe within $48 \mathrm{~h}$.

Patients who developed atrial fibrillation received treatment according to their condition. If they were haemodynamically unstable, electrical cardioversion (synchronized adjusted at 100 joules using biphasic electrical cardiovertor) was applied. If they were haemodynamically stable, pharmacological cardioversion (amiodarone $5 \mathrm{mg} / \mathrm{kg}$ intravenous over 60 minutes, then 1.2 grams per day by continuous intravenous infusion) was used [5].

\subsection{Sample Size Estimation}

To show a difference in the incidence of atrial fibrillation with $p$-value $<0.05$ and power $80 \%$, we needed a sample size of 88 patients per group for the comparison of the effect of bisoprolol versus corticosteroid and bisoprolol combination for guarding against atrial fibrillation after on-pump coronary artery bypass graft surgery.

\subsection{Statistical Analysis}

Analysis of information was done by IBM computer using SPSS (statistical program for social science, version 16) as follows:

- Presentation of quantitative variables as mean $\pm \mathrm{SD}$.

- Presentation of qualitative variables as number and percentage.

Statistical analysis was performed using statistical tests including Student's t-test, Chi-square test and table analysis. $P$ value $<0.05$ wasconsidered significant.

\section{RESULTS}

The studies included eighty-eight patients undergoing onpump CABG and received bisoprolol for prophylaxis against atrial fibrillation (Group A) who were matched with a further eighty-eight patients undergoing on-pump $\mathrm{CABG}$ and received 
bisoprolol and hydrocortisone combination for prophylaxis against atrial fibrillation (Group B). The pre-operative and intra-operative variables for each group are demonstrated in Tables $\mathbf{1}$ and $\mathbf{2}$.

The two groups were nearly similar with no statistically significant differences in terms of gender, pre-operative use of $\beta$-blockers, previous MI, left ventricular ejection fraction, hypertension, diabetes mellitus and surgical data including left internal thoracic artery usage and right coronary artery or posterior descending artery grafting. Post-operative clinical information and adverse outcomes are given in Table $\mathbf{3}$ and Fig. (1-3).

Table 1. Characteristics of patients of the two study groups.

\begin{tabular}{|c|c|c|c|}
\hline Variables & $\begin{array}{c}\text { Group A } \\
(\mathbf{n = 8 8})\end{array}$ & $\begin{array}{c}\text { Group B } \\
(\mathbf{n = 8 8})\end{array}$ & $\boldsymbol{P}$-value \\
\hline Male: Female & $\begin{array}{c}67: 21 \\
(76.14 \%) \\
\mathrm{M}\end{array}$ & $\begin{array}{c}58: 30 \\
(65.90 \%) \\
\mathrm{M}\end{array}$ & $P=0.183$ \\
\hline Diabetes Mellitus & $17(19.32 \%)$ & $21(23.86 \%)$ & $P=0.583$ \\
\hline Hypertension & $47(53.4 \%)$ & $52(59.09 \%)$ & $P=0.542$ \\
\hline Hypercholesterolemia & $42(47.7 \%)$ & $35(39.77 \%)$ & $P=0.363$ \\
\hline Previous MI & $34(38.6 \%)$ & $31(35.22 \%)$ & $P=0.757$ \\
\hline Lt ventricular ejection fraction (\%) & $48.3 \pm 6.2$ & $48.9 \pm 7.1$ & $P=0.551$ \\
\hline Creatinine (mg/d) & $1.01 \pm 0.41$ & $1.1 \pm 0.38$ & $P=0.132$ \\
\hline COPD & $7(7.95 \%)$ & $12(13.63 \%)$ & $P=0.331$ \\
\hline B.Blockers & $32(36.36 \%)$ & $34(38.63 \%)$ & $P=0.905$ \\
\hline
\end{tabular}

When $P$ value $>0.05=$ Non- significant

Table 2. Intra-operative data.

\begin{tabular}{|c|c|c|c|}
\hline Variables & $\begin{array}{c}\text { Group A } \\
(\mathbf{n = 8 8})\end{array}$ & $\begin{array}{c}\text { Group B } \\
(\mathbf{n}=\mathbf{8 8})\end{array}$ & $\boldsymbol{P}$-value \\
\hline Cross - clamp time (min.) & $73.6 \pm 25.4$ & $74.2 \pm 16.3$ & $P=0.852$ \\
\hline Cardiopulmonary bypass time (min.) & $94.5 \pm 32.7$ & $95.6 \pm 22.6$ & $P=0.795$ \\
\hline Lt internal mammary Artery usage & $82(93.2 \%)$ & $79(89.8 \%)$ & $P=0.590$ \\
\hline RCA or PDA & $41(46.6 \%)$ & $44(50 \%)$ & $P=0.783$ \\
\hline
\end{tabular}

Where if $P>0.05=$ Non- significant

Table 3. Post-operative data and adverse outcomes.

\begin{tabular}{|c|c|c|c|}
\hline Variable & $\begin{array}{c}\text { Group A } \\
(n=88)\end{array}$ & $\begin{array}{c}\text { Group B } \\
(\mathrm{n}=\mathbf{8 8})\end{array}$ & $P$-value \\
\hline Atrial fibrillation & $42(47.7 \%)$ & $26(29.5 \%)$ & $\begin{array}{c}P=0.020^{*} \\
\text { (Significant) }\end{array}$ \\
\hline Death & - & - & - \\
\hline Post - operative MI & $3(3.41 \%)$ & $1(1.13 \%)$ & $P=0.610$ \\
\hline Chest infection & $4(4.54 \%)$ & $8(9.09 \%)$ & $P=0.368$ \\
\hline Serum potassium level before AF (mmol/L) & $4.2 \pm 0.35$ & $4.1 \pm 0.43$ & $P=0.092$ \\
\hline Inotropic support & $40(45.5 \%)$ & $39(44.3 \%)$ & $P=0.742$ \\
\hline Drainage $(\mathrm{ml})$ & $496.5 \pm 150.3$ & $474.3 \pm 131.6$ & $P=0.298$ \\
\hline Duration of Hospital stay (days) & $7.2 \pm 1.6$ & $6.5 \pm 1.2$ & $\begin{array}{l}P=0.003 * \\
\text { (Significant) }\end{array}$ \\
\hline Postoperative mediastinitis (\%) & - & - & - \\
\hline Superficial wound infections & - & - & - \\
\hline $\begin{array}{c}\text { Postoperative CRP levels(mg/l) } \\
1^{\text {st }} \text { post-operative day } \\
2^{\text {nd }} \text { post-operative day }\end{array}$ & $\begin{array}{l}67.2 \pm 30.9 \\
161 \pm 48.0\end{array}$ & $\begin{array}{l}58.0 \pm 26.9 \\
118 \pm 38.7\end{array}$ & $\begin{array}{l}<0.036^{*} \text { (Significant) } \\
<0.0001^{*} \text { (Significant) }\end{array}$ \\
\hline
\end{tabular}

Where if $P>0.05=$ Non- significant, $\mathrm{P}<0.05=$ significant 


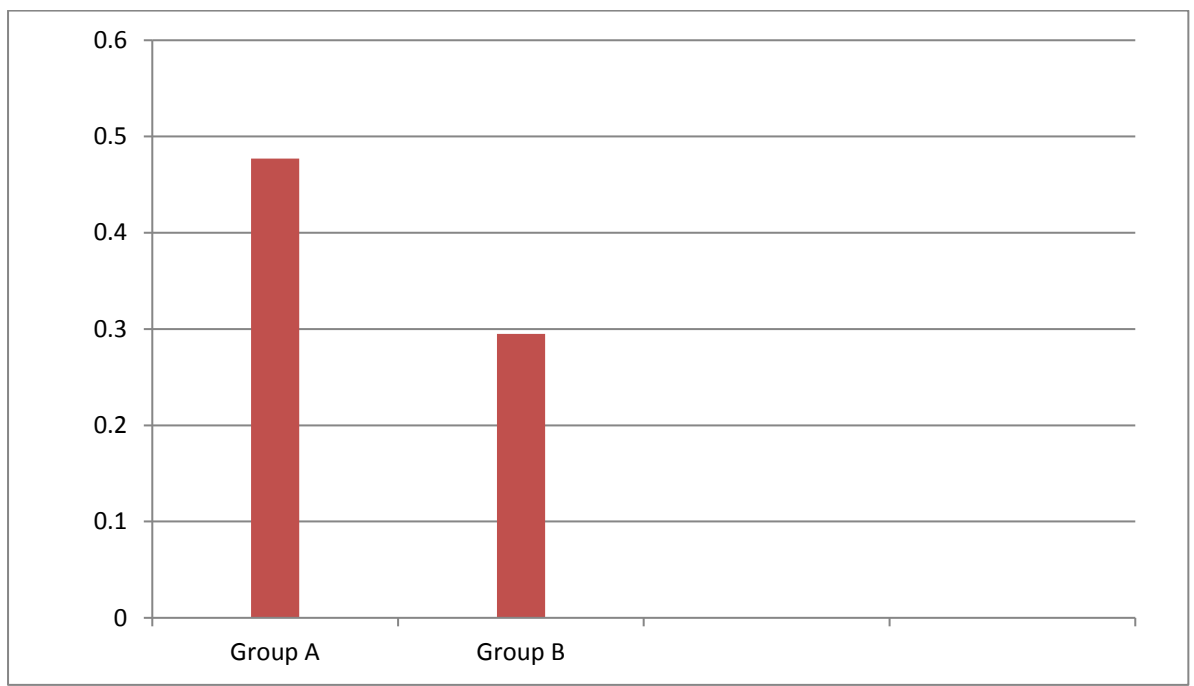

Fig. (1). Incidence of atrial fibrillation (\%).

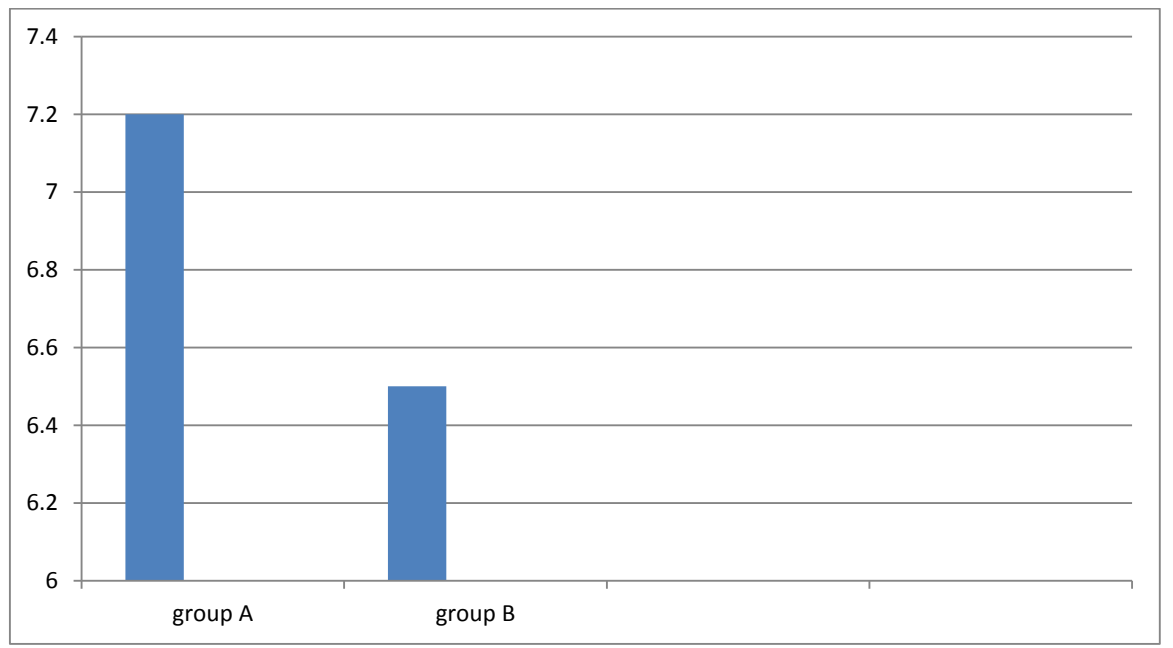

Fig. (2). Length of Hospital stay (days).

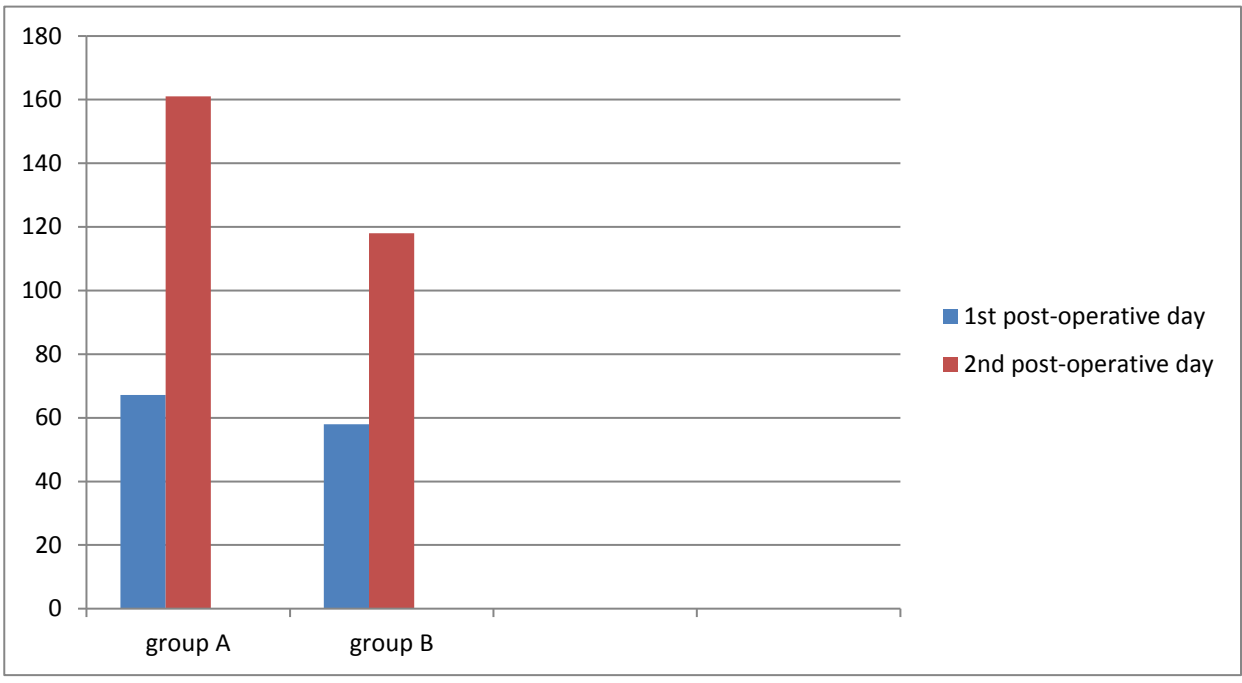

Fig. (3). Postoperative CRP levels (mg/l). 
The overall incidence of atrial fibrillation was $39 \%$, being $23.9 \%$ in group A and $15.1 \%$ in group B; this difference was statistically significant between both groups. Normal sinus rhythm was maintained by extra antiarrhythmic medication or electrical cardioversion technique in each patient developed atrial fibrillation. The duration of hospital stay was significantly longer in group A than in group B. The two groups showed no statistically significant differences with respect to postoperative infection, myocardial infarction, stroke, mediastinitis, conduction disturbances or resternotomy caused by hemorrhage. There were no psychiatric disorders in the two study groups. The concentrations of C-reactive protein on the $1^{\text {st }}$ and $2^{\text {nd }}$ postoperative days were decreased significantly in group B than in group A. No deaths occurred during our study.

\section{DISCUSSION}

Despite advances in Extracorporeal Circulation (ECC), cardioplegic arrest, surgical techniques, the appearance of new $\mathrm{AF}$ in the postoperative period was still frequent after coronary artery bypass graft, possibly due to increased age and disease of patients undergoing coronary artery bypass and continuous monitoring technology. Various preoperative and postoperative factors, including aging, hypertension, stopping beta blockers, hemorrhage and right coronary artery stenosis, are all suspected to increased AF occurrence after surgery. AF prevention strategies focused primarily on anti-arrhythmic drugs such as digitals, $\beta$-blockers, calcium channel blockers, and amiodarone [6].

Initiation of cardiopulmonary bypass under corticosteroid cover has been found to decrease the incidence of perioperative myocardial injury.

In a study by Giomarelli et al., steroid pretreatment was compared to placebo for patients undergoing on-pump cardiac surgery. Their protocol involved administration of $1 \mathrm{gm}$ methylprednisolone preoperatively and $125 \mathrm{mg}$ at the termination of cardiopulmonary bypass with similar four doses 6 hours apart given in the intensive care unit. They found a marked decrease in proinflammatory cytokines namely, Interleukin-6, IL-8and TNF- $\alpha$, with greater release of anti-inflammatory IL-10 which reduces neutrophil adhesion to endothelial cells [7].

Randomized trials performed prospectively in non-surgical patients indicated that corticosteroid therapy reduced the risk of repeated and permanent $\mathrm{AF}$ in patients who were recovered from their first attack of AF [8].

Effects of corticosteroid therapy in postoperative AF were studied in two other randomized controlled trials as the primary endpoint. Prasongsukarn et al. [8] investigated 86 patients scheduled for CABG operation who were given $1000 \mathrm{mg}$ of methylprednisolone or placebo prior to surgery and $4 \mathrm{mg}$ dexamethasone or placebo every 6 hours for one day after surgery. Postoperative AF incidence was significantly decreased in the corticosteroid group than in the placebo group (21\% versus 51 respectively) [9].

Halvorsen et al. [10] used $4 \mathrm{mg}$ dexamethasone or placebo given after initiation of anesthesia and on the first morning of the day after surgery in 300 patients undergoing CABG surgery. They failed to show the effect of corticosteroids on reduced AF occurrence after surgery. This is against our study which revealed a significant reduction of the occurrence of postoperative $\mathrm{AF}$ in group (B) where corticosteroids were used.

Another study worth-mentioning is by Rubens et al. [11] which included 68 patients who underwent coronary artery bypass graft surgery; prior to surgery, they were given an intravenous infusion of $1000 \mathrm{mg}$ methylprednisolone or placebo. Methylprednisolone has a statistically significant inhibitory effect on the occurrence of postoperative atrial fibrillation (12\% in the treatment group vs. $34 \%$ in the placebo group). This coincides with our study which demonstrated a decrease of postoperative AF where corticosteroids were used in (group B).

Yared et al. [12] examined 235 patients who underwent coronary artery bypass surgery or valve surgery. Patients were given one dose of $0.6 \mathrm{mg} / \mathrm{kg}$ dexamethasone or placebo after initiation of anesthesia. In comparison to the placebo group, dexamethasone group had a lower rate of postoperative atrial fibrillation ( $19 \% v$ vs. $32 \%$, respectively). However, $\mathrm{AF}$ after surgery was not the primary endpoint in these studies and there is no prospective identification of atrial fibrillation. Therefore, these studies were not designed initially to address the effects of corticosteroids on atrial fibrillation after surgery, but on the stimulation of the pathways of inflammation, coagulation and recovery of cardiac surgery.

Baker et al. [13] conducted a meta-analysis on the role of corticosteroids in the occurrence of atrial fibrillation after heart surgery. Nine studies involving 990 patients were investigated in their work and corticosteroids were found to decrease significantly the probability of patients with atrial fibrillation after surgery by $45 \%$ [13].

Another meta-analysis of 50 controlled randomized trials and 3323 patients demonstrated that corticosteroid prevention decreased the risk of atrial fibrillation [14].

The postoperative AF treatment goals are control of ventricular rate, anticoagulation, and conversion to normal sinus rhythm . Recently, interest in the procedure of CABG on the beating heart gave us the opportunity to investigate the effect of ECC and cardioplegic arrest on AF after off-pump CABG surgery. Several studies have reported that postoperative $\mathrm{AF}$ is reduced after off-pump $\mathrm{CABG}$, while others do not show any significant reduction [15].

It is known that the use of extracorporeal circulation during cardiac surgery is associated with a systemic inflammatory reaction that is partly responsible for postoperative atrial fibrillation. C-reactive protein complex leveland white blood cell count (inflammatory response markers) are higher in patients with atrial fibrillation. Corticosteroids showed antiinflammatory effects and reduced exaggerated inflammatory response [16]; this goes with our study which demonstrated a significant decrease of the concentration of CRP postoperatively in group (B) where corticosteroids were used than in group A.

A trial of Daoud et al. [17] showed that the incidence of atrial fibrillation was $61 \%$ in the placebo group in patients who 
received beta- blockers and $33 \%$ in patients who did not receive beta-blockers.

Solomon et al. [18] used beta-blockers all over the hospital stay in the patients randomly assigned to the amiodarone group to prevent atrial fibrillation occurrence due to the withdrawal of beta- blockers but it did not affect atrial fibrillation occurrence in groups which received the treatment.

The efficacy and safety of oral bisoprolol were studied many years ago to prevent AF after cardiac surgery. These studies showed that both bisoprolol and propranolol were effective in AF prevention compared with placebo. But there was a trend toward more common side effects which was reported in the propranolol therapy group [19].

The effectiveness of beta-blockers for AF prevention after cardiac surgery has been shown in many studies. Four metaanalyses showed that beta-blocker prophylaxis decreased atrial fibrillation after cardiac surgery. According to one meta-analysis, the type of beta-blocker or the dose does not affect the effectiveness of prevention [20].

Yaziciolglu and co-workers [21] demonstrated that the combination of digoxin and beta blockers is more effective than beta-blockers alone to prevent AF after cardiac surgery.

The study by Balcetyte-Harris et al. [22] investigated the efficacy and safety of esmolol (intravenous beta-blockers) and oral beta-blockers The study was terminated when the provisional analysis showed a significant increase in the occurrence of adverse events in the group given intravenous esmolol and no decrease in $\mathrm{AF}$ incidence in such a group.

The effectiveness and safety of propranolol have been previously investigated by Abel et al. [19] who demonstrated a significant decrease of AF after on-pump cardiac surgery when intravenous propranolol was used compared to the placebo group.

The effect of beta-blockers on AF prophylaxis was confirmed after cardiac surgery. According to the current guidelines, every patient undergoing cardiac surgery should be given beta-blocker preventive therapy for AF if there are no contraindications for its use [20].

\section{CONCLUSION}

This study demonstrated that the use of bisoprolol and hydrocortisone combination for prophylaxis against atrial fibrillation after onpump coronary artery bypass graft surgery is more effective than the use of bisoprolol only. This study opens the field for intensive research to find much more effective therapy for the prevention of atrial fibrillation after on-pump coronary artery bypass surgery.

\section{LIST OF ABBREVIATIONS}

$$
\begin{array}{ll}
\text { AF } & =\text { Atrial Fibrillation. } \\
\text { CABG } & =\text { Coronary Artery Bypasses Graft. } \\
\text { ECG } & =\text { Electrocardiography. } \\
\text { SPSS } & =\text { Statistical Program for Social Science. } \\
\text { LV } & =\text { Left Ventricle. }
\end{array}
$$

$$
\begin{array}{ll}
\text { SD } & =\text { Standard eviation. } \\
\text { MI } & =\text { Myocardial Infarction. } \\
\text { RCA } & =\text { Right Coronary Artery. } \\
\text { PDA } & =\text { Posterior Descending Artery. } \\
\text { ECC } & =\text { Extracorporeal Circulation. } \\
\text { CRP } & =\text { C-Reactive Protein. }
\end{array}
$$

\section{ETHICS APPROVAL AND CONSENT TO} PARTICIPATE

The study was approved by the ethical committee of the Ain Shams University (file reference no FMASU R 89/2018).

\section{HUMAN AND ANIMAL RIGHTS}

No Animals were used in this research. All human research procedures followed were in accordance with the ethical standards of the committee responsible for human experimentation (institutional and national), and with the Helsinki Declaration of 1975, as revised in 2013.

\section{CONSENT FOR PUBLICATION}

Written informed consent from all patients was obtained.

\section{AVAILABILITY OF DATA AND MATERIALS}

Not applicable.

\section{FUNDING}

None.

\section{AUTHORS' CONTRIBUTIONS}

RM provided the acquisition of data, did the analysis and interpretation of the data, drafted the manuscript and revised the manuscript. AM contributed to the study conception and design. MS read and approved the final manuscript.

\section{CONFLICT OF INTEREST}

The authors declare no conflict of interest, financial or otherwise.

\section{ACKNOWLEDGEMENTS}

This study was done in the cardiothoracic surgery intensive care unit of Ain Shams university educational hospital, Cairo, Egypt.

\section{REFERENCES}

[1] Mathew JP, Parks R, Savino JS, et al. Atrial fibrillation following coronary artery bypass graft surgery: Predictors, outcomes, and resource utilization. MultiCenter Study of Perioperative Ischemia Research Group. JAMA 1996; 276(4): 300-6.

[http://dx.doi.org/10.1001/jama.1996.03540040044031] [PMID: 865 6542]

[2] Møller CH, Penninga L, Wetterslev J, Steinbrüchel DA, Gluud C. Clinical outcomes in randomized trials of off- $v s$. on-pump coronary artery bypass surgery: Systematic review with meta-analyses and trial sequential analyses. Eur Heart J 2008; 29(21): 2601-16. [http://dx.doi.org/10.1093/eurheartj/ehn335] [PMID: 18628261]

[3] Turk T, Vural H, Eris C, Ata Y, Yavuz S. AF after Off-pump Coronary Artery Surgery: A prospective, matched study. J Int Med Res 2007; 35: 134-42.

[http://dx.doi.org/10.1177/147323000703500115] [PMID: 17408065] 
[4] Hashimoto K, Ilstrup DM, Schaff HV. Influence of clinical and hemodynamic variables on risk of supraventricular tachycardia after coronary artery bypass. J Thorac Cardiovasc Surg 1991; 101(1): 56-65.

[PMID: 1986170]

[5] Galve E, Rius T, Ballester R, et al. Intravenous amiodarone in treatment of recent-onset atrial fibrillation: Results of a randomized, controlled study. J Am Coll Cardiol 1996; 27(5): 1079-82.

[http://dx.doi.org/10.1016/0735-1097(95)00595-1] [PMID: 8609324]

[6] Rostagno C. Recent Developments in Pharmacologic Prophylaxis of $\mathrm{AF}$ in Patients Undergoing Surgical Revascularization. Cardiovasc Hematol Agents Med Chem 2009; 7: 137-46.

[http://dx.doi.org/10.2174/187152509787847074] [PMID: 19355875]

[7] Giomarelli P, Scolletta S, Borrelli E, Biagioli B. Myocardial and lung injury after cardiopulmonary bypass: Role of interleukin (IL)-10. Ann Thorac Surg 2003; 76(1): 117-23.

[http://dx.doi.org/10.1016/S0003-4975(03)00194-2] [PMID: 1284 2524]

[8] Dernellis J, Panaretou M. Relationship between C-reactive protein concentrations during glucocorticoid therapy and recurrent atrial fibrillation. Eur Heart J 2004; 25(13): 1100-7. [http://dx.doi.org/10.1016/j.ehj.2004.04.025] [PMID: 15231367]

[9] Prasongsukarn K, Abel JG, Jamieson WR, et al. The effects of steroids on the occurrence of postoperative atrial fibrillation after coronary artery bypass grafting surgery: A prospective randomized trial. J Thorac Cardiovasc Surg 2005; 130(1): 93-8.

[http://dx.doi.org/10.1016/j.jtcvs.2004.09.014] [PMID: 15999046]

[10] Halvorsen P, Raeder J, White PF, et al. The effect of dexamethasone on side effects after coronary revascularization procedures. Anesth Analg 2003; 96(6): 1578-83

[http://dx.doi.org/10.1213/01.ANE.0000063922.90966.3A] [PMID: 12 760978]

[11] Rubens FD, Nathan H, Labow R, et al. Effects of methylprednisolone and a biocompatible copolymer circuit on blood activation during cardiopulmonary bypass. Ann Thorac Surg 2005; 79(2): 655-65. [http://dx.doi.org/10.1016/j.athoracsur.2004.07.044] [PMID: 15680 854]

[12] Yared JP, Bakri MH, Erzurum SC, et al. Effect of dexamethasone on atrial fibrillation after cardiac surgery: Prospective, randomized, double-blind, placebo-controlled trial. J Cardiothorac Vasc Anesth 2007; 21(1): 68-75.

[http://dx.doi.org/10.1053/j.jvca.2005.10.014] [PMID: 17289483]

[13] Baker WL, White CM, Kluger J, Denowitz A, Konecny CP, Coleman CI. Effect of perioperative corticosteroid use on the incidence of postcardiothoracic surgery atrial fibrillation and length of stay. Heart Rhythm 2007; 4(4): 461-8. [http://dx.doi.org/10.1016/j.hrthm.2006.11.026] [PMID: 17399635]

14] Baker WL, White CM, Coleman CI. Letter by Baker et al regarding article, "benefits and risks of corticosteroid prophylaxis in adult cardiac surgery: A dose-response meta-analysis". Circulation 2009; 120(20): e163.

[http://dx.doi.org/10.1161/CIRCULATIONAHA.109.872242] [PMID: 19917892]

[15] Siebert J, Rogowski J, Jagielak D, Anisimowicz L, Lango R, Narkiewicz M. Atrial fibrillation after coronary artery bypass grafting without cardiopulmonary bypass. Eur J Cardiothorac Surg 2000; 17: 520-3.

[16] Lamm G, Auer J, Weber T, Berent R, Ng C, Eber B. Postoperative white blood cell count predicts atrial fibrillation after cardiac surgery. J Cardiothorac Vasc Anesth 2006; 20(1): 51-6.

[http://dx.doi.org/10.1053/j.jvca.2005.03.026] [PMID: 16458214]

[17] Daoud EG, Dabir R, Archambeau M, Morady F, Strickberger SA Randomized, double-blind trial of simultaneous right and left atrial epicardial pacing for prevention of post-open heart surgery atrial fibrillation. Circulation 2000; 102(7): 761-5.

[http://dx.doi.org/10.1161/01.CIR.102.7.761] [PMID: 10942744

[18] Solomon AJ, Greenberg MD, Kilborn MJ, Katz NM. Amiodarone versus a beta-blocker to prevent atrial fibrillation after cardiovascular surgery. Am Heart J 2001; 142(5): 811-5.

[http://dx.doi.org/10.1067/mhj.2001.118738] [PMID: 11685167]

[19] Abel RM, van Gelder HM, Pores IH, Liguori J, Gielchinsky I, Parsonnet V. Continued propranolol administration following coronary bypass surgery. Antiarrhythmic effects. Arch Surg 1983; 118(6): 727-31.

[http://dx.doi.org/10.1001/archsurg.1983.01390060045010] [PMID: 66 01941]

[20] Dunning J, Treasure T, Versteegh M, Nashef SA. Guidelines on the prevention and management of de novo atrial fibrillation after cardiac and thoracic surgery. Eur J Cardiothorac Surg 2006; 30(6): 852-72. [http://dx.doi.org/10.1016/j.ejcts.2006.09.003] [PMID: 17070065]

[21] Yazicioglu L, Eryilmaz S, Sirlak M, et al. The effect of preoperative digitalis and atenolol combination on postoperative atrial fibrillation incidence. Eur J Cardiothorac Surg 2002; 22(3): 397-401.

[http://dx.doi.org/10.1016/S1010-7940(02)00308-1] [PMID: 12204 730]

[22] Balcetyte-Harris N, Tamis JE, Homel P, Menchavez E, Steinberg JS. Randomized study of early intravenous esmolol versus oral betablockers in preventing post-CABG atrial fibrillation in high risk patients identified by signal-averaged ECG: Results of a pilot study. Ann Noninvasive Electrocardiol 2002; 7(2): 86-91. [http://dx.doi.org/10.1111/j.1542-474X.2002.tb00147.x] [PMID: 120 49678]

\section{(C) 2019 Mahrose et al.}

This is an open access article distributed under the terms of the Creative Commons Attribution 4.0 International Public License (CC-BY 4.0), a copy of which is available at: (https://creativecommons.org/licenses/by/4.0/legalcode). This license permits unrestricted use, distribution, and reproduction in any medium, provided the original author and source are credited. 